\title{
The Effect of Bronchial Blood Flow on Hyperpnea-induced Airway Obstruction and Injury
}

\author{
Arthur N. Freed, Chiharu Omori, * and Brian H. Schofield \\ Department of Environmental Health Sciences, The Johns Hopkins University, Baltimore, Maryland 21205; and *The First Department \\ of Internal Medicine, Nihon University School of Medicine, 30-1 Oyaguchikamimachi Itabashiku, Tokyo, 173 Japan
}

\begin{abstract}
We examined the effect of bronchial blood flow (BBF) on hyperpnea-induced airway obstruction (HIAO) in dogs. HIAO in in situ isolated pulmonary lobes with or without BBF was monitored via a bronchoscope. An intravascular tracer in conjunction with morphometric analysis was used to document the efficacy of our occlusion technique. We found that $(a)$ Occlusion of the bronchial artery abolished bronchovascular leakage, but did not alter HIAO; (b) HIAO occurred in postmortem dogs, and was attenuated by cooling; (c) absence of BBF did not cause mucosal damage, although hyperpnea-induced injury was enhanced in airways lacking BBF; (d) BBF did not affect either goblet/ ciliated cell ratios or hyperpnea-induced goblet cell degranulation; $(e)$ ligation of the bronchial artery and hyperpnea each caused mast cell degranulation, and these effects were additive; $(f)$ hyperpnea-induced leukocyte infiltration was reduced in the absence of BBF; and $(g$ ) ligation of the bronchial artery and hyperpnea with dry air each increased airway vessel diameter, and these effects were additive. We conclude that either impairment or absence of BBF abolishes bronchovascular leakage and increases hyperpnea-induced mucosal injury, but fails to affect HIAO. Based on these results we speculate that bronchovascular leakage protects the bronchial mucosa from excessive losses of heat and water, and inhibits mucosal damage. (J. Clin. Invest. 1995. 96:1221-1229.) Key words: airway resistance - airway injury $\bullet$ bronchial circulation $\bullet$ bronchovascular leakage $\bullet$ dog
\end{abstract}

Address correspondence to Dr. Arthur N. Freed, Division of Physiology, The Johns Hopkins University, 615 North Wolfe Street, Rm. 7006, Baltimore, MD 21205. Phone: 410-955-3515; 410-955-0299.

Received for publication 10 January 1995 and accepted in revised form 25 May 1995.

1. Abbreviations used in this paper: $\mathrm{AR}$, airway rings; $\mathrm{BBF}$, bronchial blood flow; CS, cross-section, d, distance; $\mathrm{D}=P_{\mathrm{bm}} / \pi$ maximally relaxed equivalent bronchial diameter; DAC, dry air challenge, $D_{\text {aw }}$ airway diameter; $D_{\max }$, maximum vessel diameter; $D_{\min }$, perpendicular vessel diameter; $D_{\mathrm{v} 1}=P_{\mathrm{v} 1} / \pi$, vascular internal diameter; $\mathrm{G} / \mathrm{C}$, goblet $/$ ciliated cell ratio; HIAO, hyperpnea-induced airway obstruction; I, intact; LLL, left lower lobe; O, occluded; PA, pulmonary artery; PAS, periodic acidSchiff; $P_{\mathrm{b}}$ baseline peripheral airway pressure; $P_{\mathrm{bm}}$, perimeter of the basement membrane; PCWP, pulmonary capillary wedge pressure; $P_{\mathrm{pa}}$ lobar arterial pressure; $P_{\mathrm{v} 1}$ vascular internal perimeter; RLL, right lower lobe; $r$, Pearson's correlation coefficient; $r_{\mathrm{s}}$ Spearman's rank analysis coefficient; $T_{\mathrm{aw}}$ airway wall temperature; TB, toluidine blue; and $T_{\mathrm{pa}}$, lobar arterial temperature.

J. Clin. Invest.

(c) The American Society for Clinical Investigation, Inc.

$0021-9738 / 95 / 09 / 1221 / 09 \$ 2.00$

Volume 96, September 1995, 1221-1229

\section{Introduction}

Hyperventilation with dry air increases airway resistance in guinea pigs (1), rabbits (2), cats (3), dogs (4), monkeys (5), and humans (6). Other studies reveal that it damages the bronchial mucosa $(7,8)$, increases bronchial blood flow $(9,10)$, and increases bronchovascular permeability $(8,11)$. All of these phenomena are consistent with the hypothesis that hyperpneainduced airway obstruction (HIAO) ${ }^{1}$ is a result of bronchovascular hyperemia and edema formation (12). Although some studies provide data that indirectly address this hypothesis (13, 14 ), there are no data that directly document these phenomena. If bronchovascular congestion and leakage were a prerequisite for the development of HIAO, then reduction or elimination of bronchial blood flow (BBF) should inhibit or abolish this response. The purpose of this study was to determine the role of the bronchial circulation in the development of HIAO.

\section{Methods}

Dogs were handled and maintained in accordance with the standards set forth in the Policy and Procedures Manual published by the Johns Hopkins University School of Hygiene and Public Health's Animal Care and Use Committee. Male mongrel dogs (mean weight \pm se $=20.1 \pm 0.8$ $\mathrm{kg}, n=19)$ were anesthetized with pentobarbital sodium (30 mg/ $\mathrm{kg}$, iv), and supplemented with pentobarbital ( $30 \mathrm{mg}$, iv) as needed. Anesthetic depth was assessed by heart rate, blood pressure, canthal reflex, and the presence of spontaneous movement or breathing. A tracheotomy was performed, a dual portal tracheal tube inserted, and the dog was ventilated with room air at a tidal volume of $17 \mathrm{ml} / \mathrm{kg}$ via a constant volume ventilator. Respiratory rate was adjusted to maintain end-tidal $\mathrm{CO}_{2}$ between 4.0 and $4.5 \%$. Heart rate and mean arterial pressure were monitored throughout all experimental trials via a catheter placed in the femoral artery. The femoral vein was also catheterized for infusion of fluids and drugs. Rectal temperature was monitored and maintained with a warming pad during the course of the experiment.

Measurements of peripheral airway pressure and airway wall temperature

A fiberoptic bronchoscope (Olympus BF Type P10, Olympus Corp. of America, New Hyde Park, NY) was visually guided and wedged in a sublobar bronchus. Dry room temperature $5 \% \mathrm{CO}_{2}$ in air was delivered to the wedged segment at a constant flow rate $(200 \mathrm{ml} / \mathrm{min})$ through one lumen of a dual lumen catheter that was inserted through the suction port of the bronchoscope. The other lumen was used to record pressure at the tip of the scope $\left(P_{\mathrm{b}}\right)$. With ventilator stroke and frequency fixed, changes in end-expiratory $P_{\mathrm{b}}$ reflect changes in peripheral airway resistance. In experiments involving the measurement of airway wall temperature $\left(T_{\mathrm{aw}}\right), \mathrm{a} 5 \mathrm{~F}$ Swan-Ganz thermodilution catheter with the thermistor exposed at its tip was threaded through the suction port of the bronchoscope and used to simultaneously measure $T_{\mathrm{aw}}$ and $P_{\mathrm{b}}$ during dry air challenge (15).

Dry air challenge (DAC)

Insufflation of dry $5 \% \mathrm{CO}_{2}$ in air was increased from 200 to $1,500-$ $2,000 \mathrm{ml} / \mathrm{min}$ for either a 2 - or 5 -min period. The flow rate was then returned to $200 \mathrm{ml} / \mathrm{min}$ and $P_{\mathrm{b}}$ was monitored over the next $10 \mathrm{~min}$. 


\section{Control of bronchial blood flow}

The left lower lobe's (LLL) pulmonary artery and bronchus was isolated via a left lateral thoracotomy. A $9 \times 30$-mm plastic tube was visually guided into the LLL lobar bronchus to provide internal airway support. BBF to the LLL was stopped by tightening an umbilical tape occluder placed around the isolated lobar bronchus. In some experiments, we attempted to stop and restart BBF by tightening and then loosening the umbilical tape occluder placed around the bronchus.

\section{Cooling pulmonary blood}

Pulmonary blood flow to the LLL was controlled using an open chest preparation (16). Briefly, a catheter was placed in the branch of the pulmonary artery (PA) entering the LLL. Lobar arterial pressure $\left(P_{\mathrm{pa}}\right)$ and temperature $\left(T_{\mathrm{pa}}\right)$ were measured via a modified thermodilution catheter that was inserted into and advanced to the tip of the PA catheter. Blood from the femoral vein perfused the LLL after it passed through a rotary pump $(150 \mathrm{ml} / \mathrm{min})$, a bubble trap, and a heat exchanger. The blood was rapidly cooled by switching the water intake of the heat exchanger from a $39^{\circ} \mathrm{C}$ bath to one set at $29^{\circ} \mathrm{C}$.

\section{Experimental protocols}

\section{THE EFFECT OF BRONCHIAL BLOOD FLOW ON HIAO}

Single DAC in contralateral lobes. A $5 \mathrm{~min} 2,000 \mathrm{ml} / \mathrm{min}$ DAC was done in a sublobar segment of the LLL in which the bronchial circulation was occluded throughout the entire experiment $(n=3)$. An identical DAC was simultaneously performed in a contralateral sublobar segment located in the right lower lobe.

Repeated DAC. A sublobar segment in the LLL of four dogs was repeatedly exposed to $2,000 \mathrm{ml} / \mathrm{min}$ DAC for $2 \mathrm{~min}$. Bronchial blood flow to the LLL was either intact (I) or occluded $(O)$ with a ligature during and for $15 \mathrm{~min}$ after the DAC. Sequential challenges were alternately done with and without BBF in four dogs in the following order: $\operatorname{dog} 1: \mathrm{I}, \mathrm{O}, \mathrm{I} ; \operatorname{dog} 2: \mathrm{I}, \mathrm{O}, \mathrm{I} ; \operatorname{dog} 3: \mathrm{I}, \mathrm{O}$; and $\operatorname{dog} 4: \mathrm{O}, \mathrm{I}, \mathrm{O}, \mathrm{I} . T_{\text {aw }}$ of the wedged sublobar bronchus was recorded throughout the experiment. Data from alternate trials in dogs 1,2 , and 4 were averaged and used along with the data from dog 3 for statistical analysis. $T_{\text {aw }}$ of the wedged sublobar bronchus was recorded throughout each trial and averaged accordingly.

DAC post mortem. Dogs died from cardiac arrest while anesthetized and undergoing study for a similar but unrelated experiment. Within 30 min after death, one wedged segment in an in situ isolated perfused LLL was challenged twice with a $2 \mathrm{~min} 1,500 \mathrm{ml} / \mathrm{min}$ DAC $(n=3)$. The LLL was challenged first with a $T_{\mathrm{pa}}$ of $\sim 39^{\circ} \mathrm{C}$ in two dogs; a third dog was challenged first with a $T_{\mathrm{pa}}$ of $29^{\circ} \mathrm{C}$. Approximately $15 \mathrm{~min}$ after DAC, LLL temperature was changed and a second identical challenge was repeated after $P_{\mathrm{b}}$ returned to baseline.

DRY AIR-INDUCED BRONCHOVASCULAR HYPERPERMEABILITY Extravasation of Evan's blue. Five lobes in three dogs were exposed for $5 \mathrm{~min}$ to $2000 \mathrm{ml} / \mathrm{min}$ dry airflow. Adjacent sublobar airways served as unexposed controls for each lobe. Evan's blue dye (Sigma Chemical Co., St Louis, MO) was injected ( $20 \mathrm{mg} / \mathrm{kg}$, iv) $1 \mathrm{~min}$ before the DAC and the tissues were removed as described below. Airways distal to the bronchoscope were dissected free from the parenchyma, washed in Hanks' buffered salt solution (HBSS), cut into 5-mm sections and weighed. Dye was extracted in formamide (Sigma Chemical Co.) at $55^{\circ} \mathrm{C}$ for $24 \mathrm{~h}$, quantified spectrophotometrically at $620 \mathrm{~nm}$, and expressed as $\mathrm{ng} / \mathrm{mg}$ of tissue (17).

Extravasation of colloidal label. A bronchoscope was wedged in a sublobar bronchus in seven dogs and a $5-\min 2,000 \mathrm{ml} / \mathrm{min}$ DAC was performed. Adjacent sublobar airways served as unexposed controls for each lobe. Monastral blue B (Sigma Chemical Co.) was injected ( $1 \mathrm{ml} /$ $\mathrm{kg}$, iv) $1 \mathrm{~min}$ before DAC, and the tissues were removed for analysis as described below.

Morphometric analysis of airways with or without BBF. A 5-min $2,000 \mathrm{ml} / \mathrm{min}$ DAC was done in a sublobar segment of the LLL in which the bronchial circulation was occluded throughout the entire experiment $(n=5)$. Adjacent sublobar airways served as unexposed controls for the ligated lobe. An identical DAC was done in normally perfused sublobar segments of five other dogs and adjacent sublobar airways served as unexposed controls for those lobes. After lobar bronchial artery occlusion, colloidal carbon (Faber-Castell Corp., Newark, $\mathrm{NJ}$ ) was injected ( $1 \mathrm{ml} / \mathrm{kg}$, iv) $60 \mathrm{~s}$ before the DAC to quantitatively assess dry air-induced microvascular leakage and the efficacy of our occlusion technique.

\section{Tissue removal and preparation}

Dogs were bled, a median sternotomy was done, the descending aorta was cannulated at the level of the fourth rib and clamped below the seventh, the pulmonary artery and left atrium were cannulated, and the bronchial and pulmonary vasculature were perfused with HBSS. The lungs were removed within 30-60 min after DAC and either assayed for Evan's blue content as described above or were prepared for morphometric analysis as follows. After each lobe was cannulated, Streck tissue fixative (Streck Laboratories, Omaha, NE) was instilled into each lobe to an inflation pressure of $20 \mathrm{~cm} \mathrm{H}_{2} \mathrm{O}$. Lobes were then immersed in the fixative for $24-48 \mathrm{~h}$ before dissection. After fixation, the parenchyma was dissected free from the bronchi, and the location of the bronchoscope was determined by using an airway map constructed at the beginning of the experiment. A diagram was made of the airway tree, which was cut serially into $\sim 3$-mm-long rings and labeled for analysis. The airway rings were dehydrated with ETOH and embedded in glycolmethyacrylate using a JB-4 embedding kit (Polysciences, Warrington, PA). One 2-3- $\mu \mathrm{m}$ cross-section (CS) of each airway ring was stained with periodic acid-Schiff (PAS), and one with toluidine blue (TB) and naphthol yellow S. Distance from the tip of the bronchoscope of each DAC tissue sample was determined from the airway tree diagram. Comparable distances for control tissue CSs taken from airways adjacent to the wedged sublobar segment were calculated from the airway diameter using the following regression equations derived from 194 distance-diameter measurements made in 13 of the 19 dogs used in this study: right upper lobe: $\mathrm{d}=-6.064 D_{\mathrm{aw}}+39.418(r=0.558$, df $=23, P \leq 0.002)$; right middle lobe: $\mathrm{d}=-4.842 D_{\mathrm{aw}}+33.255(r$ $=-0.618, \mathrm{df}=18, P \leq 0.002)$; right lower lobe: $\mathrm{d}=-8.911 D_{\text {aw }}$ $+43.952(r=-0.790, \mathrm{df}=45, P \leq 0.0001)$; left upper lobe: $\mathrm{d}$ $=-10.676 D_{\text {aw }}+48.898(r=-0.747, \mathrm{df}=29, P \leq 0.0001)$; left middle lobe: $\mathrm{d}=-6.205 D_{\mathrm{aw}}+35.433(r=-0.624, \mathrm{df}=44, P$ $\leq 0.0001)$; left lower lobe: $\mathrm{d}=-10.124 D_{\mathrm{aw}}+46.200(r=-0.857$, $\mathrm{df}=23, P \leq 0.0001)$.

\section{Morphometric analysis}

Airways with CSs ranging from 0.5 to $4.4 \mathrm{~mm}$ in diameter were examined using light microscopy and an image analysis system (Sigma Scan, Jandel Scientific, Corte Madera, CA). Airways $4.5 \mathrm{~mm}$ and larger were not used because of their proximity to the bronchoscope whose tip was $4.8 \mathrm{~mm}$ in diameter. All airway CS's were categorized as either bronchi (airways with cartilage) or bronchioles (noncartilaginous airways). A schematic representation of a bronchiole is depicted in Fig. 1. The relative condition of the airway mucosa was assigned to one of two categories for analysis: Normal mucosa containing ciliated and goblet cells, and damaged mucosa composed of either nonciliated or denuded airway surfaces. The perimeter of the basement membrane $\left(P_{\mathrm{bm}}\right)$ and the lengths of normal and damaged mucosa were measured. $P_{\mathrm{bm}}$, which is unaffected by changes in airway tone (18), was used to calculate the maximally relaxed equivalent bronchial diameter $\left(\mathrm{D}=P_{\mathrm{bm}} / \pi\right)$. The following measurements were made on each airway CS at a magnification of $400 \times$, and the overall average per sublobar segment was calculated for each treatment. Three to six airway CS's were evaluated from each experimental sublobar segment, and two airway CS's were examined from each control segment. Control airways were located in sublobar segments adjacent to experimental airways, but were not exposed to DAC. Ciliated cells $/ \mathrm{mm}$ and goblet cells $/ \mathrm{mm}$ of basement membrane were counted in normal mucosa of PAS stained tissues, and goblet/ ciliated cell $(\mathrm{G} / \mathrm{C})$ ratios were calculated. Goblet cells were identified via PAS staining. The number of mast cells and granulocytes within the lamina propria and submucosa of the airway wall located directly 


\section{\begin{tabular}{l|l} 
Ciliated Mucosa & Damaged Mucosa
\end{tabular}}

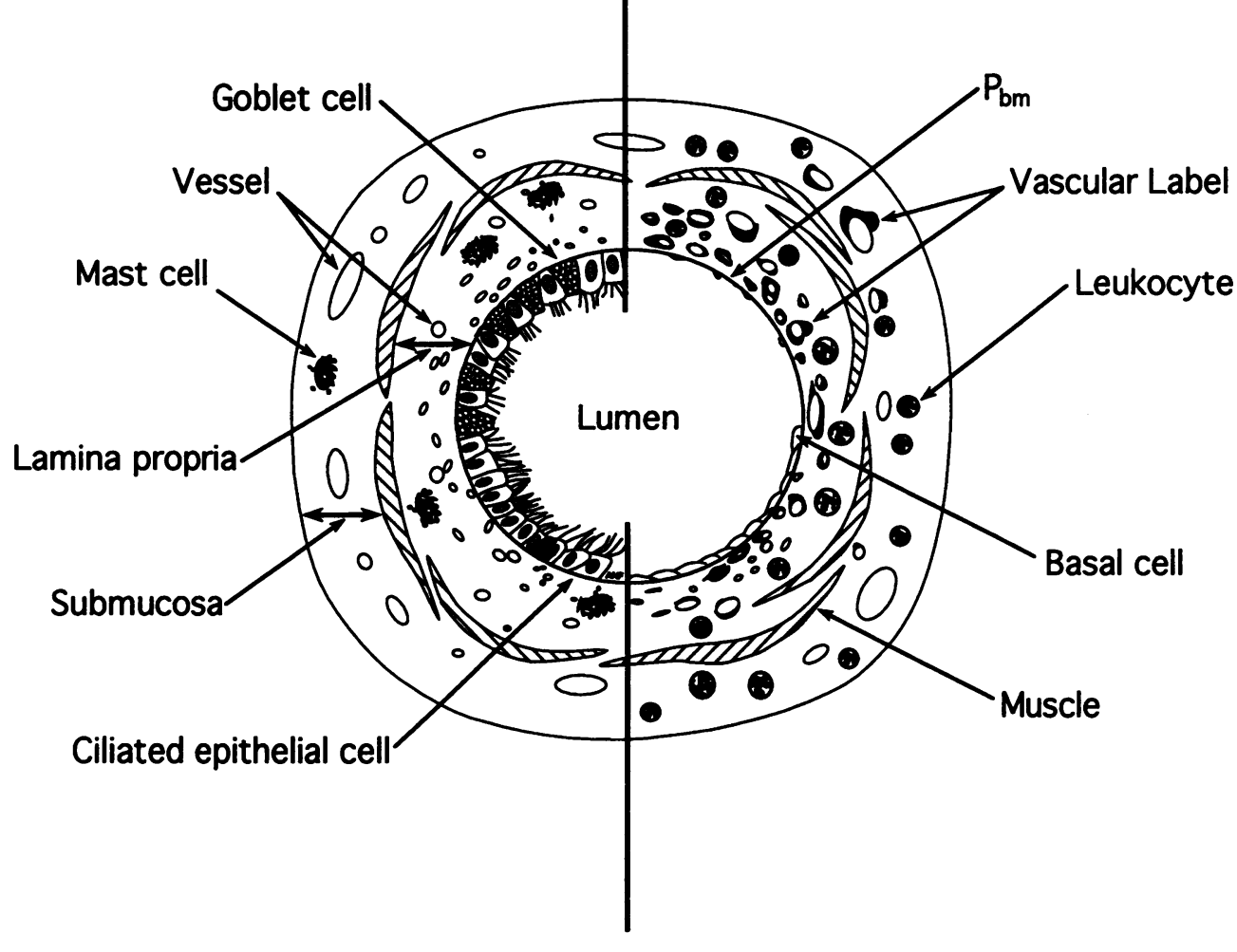

Figure 1. Schematic representation of a bronchiole showing two mucosal categories. The percentage of airway perimeter $\left(P_{\mathrm{bm}}\right)$ occupied by each mucosal category was used to calculate the average vascular label $\left(\mu \mathrm{m}^{2} / \mathrm{mm}^{2}\right)$, mast cells $/ \mathrm{mm}^{2}$, and inflammatory cells $/ \mathrm{mm}^{2}$ in each airway crosssection. below either normal or damaged mucosa were counted in CSs stained with TB. Mast cells were identified as cells that had granules stained with TB, and granulocytes were identified by their nuclei. The lamina propria of the bronchial wall was defined as tissue located between the basement membrane and the luminal border of the airway smooth muscle (19). The submucosa was defined as tissue lying outside the airway smooth muscle, excluding any muscle and cartilage present. The number of mast cells and granulocytes were expressed per $\mathrm{mm}^{2}$ of lamina propria or submucosa located below either normal or damaged mucosa. The permeability of vessels located in the lamina propria or submucosa below either normal or damaged mucosa was estimated by measuring the vascular wall area occupied by colloidal label in each airway CS stained with PAS, and bronchovascular leakage as indicated by extravasation of colloidal label was expressed as either $\mu \mathrm{m}^{2} / \mathrm{mm}$ of $P_{\mathrm{bm}}$ or as $\mu \mathrm{m}^{2} / \mathrm{mm}^{2}$ of airway tissue (Fig. 1). The diameter of airway vessels was measured in CS's stained with TB. Vessels were identified by structural characteristics of the endothelial and periendothelial cell layer, and blood cells that were sometimes present in the vascular lumen. Measurements of vascular internal perimeter $\left(P_{\mathrm{v} 1}\right)$, maximum diameter $\left(D_{\max }\right)$ and perpendicular diameter $\left(D_{\min }\right)$ of each vessel were made at $1,000 \times$. The vascular internal diameter $\left(D_{\mathrm{v} 1}=P_{\mathrm{v} 1} / \pi\right)$ of all vessels with a $D_{\max }$ / $D_{\min }$ ratio $\geq 0.75$ was used in our analysis.

\section{Statistical analysis}

Dry air-induced changes in $P_{\mathrm{b}}$ were analyzed using a two-way analysis of variance and Duncan's multiple range test. All morphometrically derived data were analyzed using Kruskal-Wallis One-Way ANOVA for comparison of treatment means. Nonparametric multiple comparisons were done in a fashion paralleling the Dunnett's test by using rank sums instead of means to compare treatments (20). Spearman's rank analysis $\left(r_{s}\right)$ was used to correlate the extravasation of Evan's blue dye with that of colloidal label. All values are expressed as the mean \pm se. Statistical significance was judged at $P \leq 0.05$.

\section{Results}

The effect of bronchial blood flow on HIAO SINGLE DAC IN CONTRALATERAL LOBES Baseline $P_{\mathrm{b}}$ just prior to DAC in the right lower lobe (RLL) and the LLL with and without BBF was $1.9 \pm 0.36$ and $3.4 \pm 0.89$ $\mathrm{cm}_{2} \mathrm{O}(n=3)$, respectively (Fig. $\left.2 A\right)$. This difference in baseline $P_{\mathrm{b}}$ is within the normal range reported in the canine lung (21). Because hyperpnea-induced changes in $P_{\mathrm{b}}$ are independent of baseline tone, $\Delta P_{\mathrm{b}}$ is useful for comparing the magnitude of HIAO in contralateral sublobar segments (21). Thus, $\Delta P_{\mathrm{b}} 5 \mathrm{~min}$ after DAC in the RLL with BBF was not different $(P=0.31)$ from that in the LLL without BBF (Fig. $2 A)$.

\section{REPEATED DAC}

No difference existed between baseline $P_{\mathrm{b}}$ preceding DAC either with $\left(2.7 \pm 0.72 \mathrm{~cm} \mathrm{H}_{2} \mathrm{O}, n=4\right)$ or without $(2.6 \pm 0.68 \mathrm{~cm}$ $\left.\mathrm{H}_{2} \mathrm{O}\right) \mathrm{BBF}$. There was also no difference $(P=0.56)$ between the $\Delta P_{\mathrm{b}}$ recorded $2 \mathrm{~min}$ after DAC either with or without $\mathrm{BBF}$ (Fig. $2 B$ ). $\Delta T_{\text {aw }}$ during DAC with and without BBF was $3.1 \pm 1.0$ and $2.9 \pm 1.2^{\circ} \mathrm{C}(n=4, P=0.993)$, respectively.

\section{DAC POST MORTEM}

When $\mathrm{T}_{\mathrm{pa}}$ was maintained at $38.5 \pm 0.3^{\circ} \mathrm{C}, P_{\mathrm{b}}$ increased from $3.9 \pm 1.36 \mathrm{~cm} \mathrm{H}_{2} \mathrm{O}$ before to $6.8 \pm 2.25 \mathrm{~cm} \mathrm{H}_{2} \mathrm{O}(n=3) 5 \mathrm{~min}$ after DAC (Fig. $2 C$ ). When $T_{\mathrm{pa}}$ was maintained at $29 \pm 0.4^{\circ} \mathrm{C}$, $P_{\mathrm{b}}$ increased from $3.9 \pm 1.51 \mathrm{~cm} \mathrm{H}_{2} \mathrm{O}$ before to $4.9 \pm 1.63 \mathrm{~cm} \mathrm{H}_{2} \mathrm{O}$ 5 min after DAC, and responses were significantly attenuated $(P$ $\leq 0.01$ ) when compared with $\Delta \mathrm{P}_{\mathrm{b}}$ recorded at normal $T_{\mathrm{pa}}$ (Fig. $2 C$ ). $\mathrm{P}_{\mathrm{pa}}$ was $19 \pm 1.9 \mathrm{mmHg}$ when warm, and averaged $23 \pm 2.5$ $\mathrm{mmHg}$ when the blood was cooled to $29^{\circ} \mathrm{C}$. 


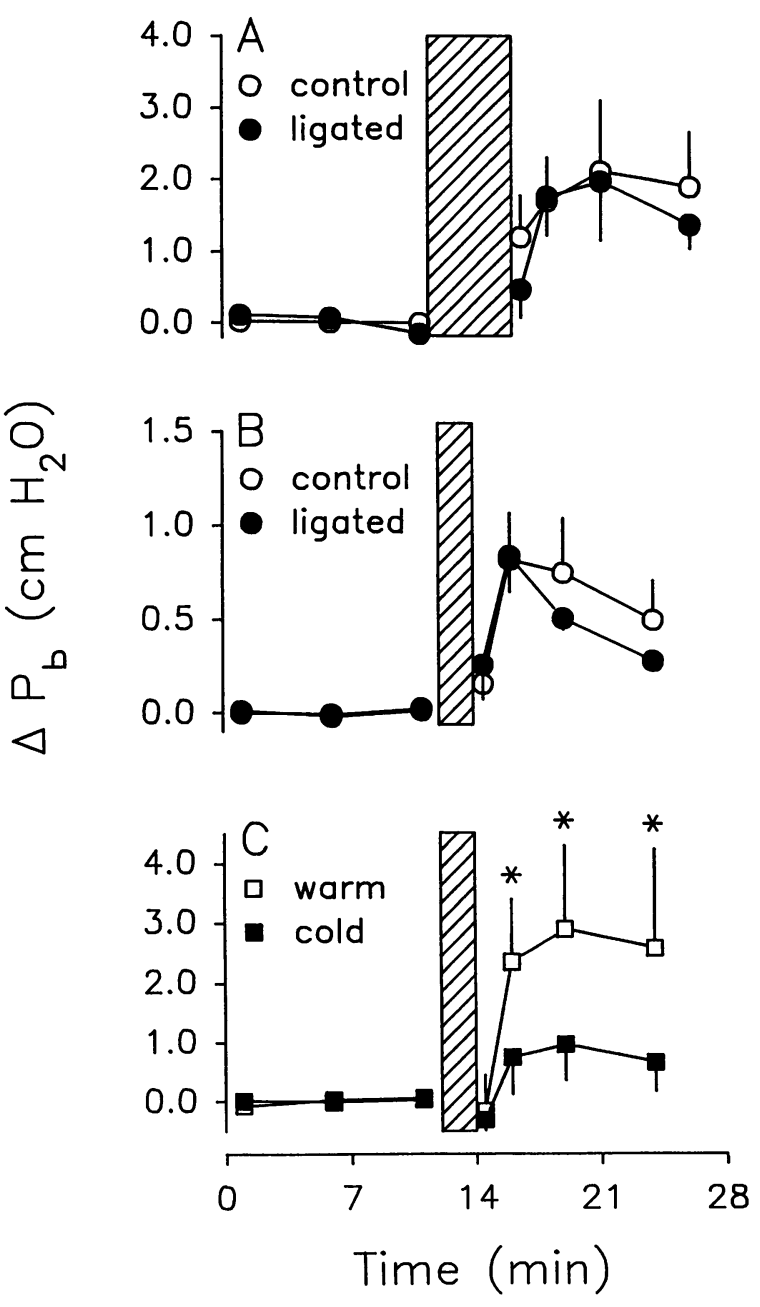

Figure 2. The effect of bronchial blood flow on hyperpnea-induced changes in sublobar pressure $\left(\Delta P_{\mathrm{b}}\right)$. (A) A $5 \mathrm{~min} 2,000 \mathrm{ml} / \mathrm{min}$ exposure to dry air was done once in either a normally perfused lobe or a contralaterally located ligated lobe $(n=3)$. (B) A sublobar segment in the left lower lobe was repeatedly exposed to $2,000 \mathrm{ml} / \mathrm{min}$ dry air for $2 \mathrm{~min}$ ( vertical bar) during either normal perfusion or after temporary ligation of the bronchial artery $(n=4)$. (C) Two consecutive dry air challenges $(1,500 \mathrm{ml} / \mathrm{min}$ for $2 \mathrm{~min})$ were done post mortem in in situ isolated perfused lobes in which pulmonary blood was maintained at either $\sim 39$ or $\sim 29^{\circ} \mathrm{C}(n=3)$. All values represent mean \pm se. $* P$ $\leq 0.05$.

\section{Hyperpnea-induced bronchovascular leakage}

\section{EXTRAVASATION OF EVAN'S BLUE}

The magnitude of dry air-induced extravasation of Evan's blue was inversely correlated $\left(r_{\mathrm{s}}=1.0, P \leq 0.0001\right)$ with distance beyond the tip of the bronchoscope (Fig. $3 \mathrm{~A}$ ). Regardless of location, control airways contained $<25 \mathrm{ng} / \mathrm{mg}$ of Evan's blue. Nonspecific tissue absorbance at $620 \mathrm{~nm}$ was negligible.

EXTRAVASATION OF COLLOIDAL LABEL

Extravasation of monastral blue was inversely correlated $\left(r_{\mathrm{s}}\right.$ $=1.0, P \leq 0.0001$ ) with distance beyond the tip of the bronchoscope (Fig. $3 B$ ). Extravasation of label was negligible in unexposed control bronchi, and was independent of bronchial diameter. Extravasation of Evan's blue (Fig. $3 A$ ) was significantly correlated $\left(r_{\mathrm{s}}=1.00, P \leq 0.001 n=6\right)$ with that of monastral blue (Fig. $3 B$ ) in identically challenged airways (Fig. $3 C$ ).
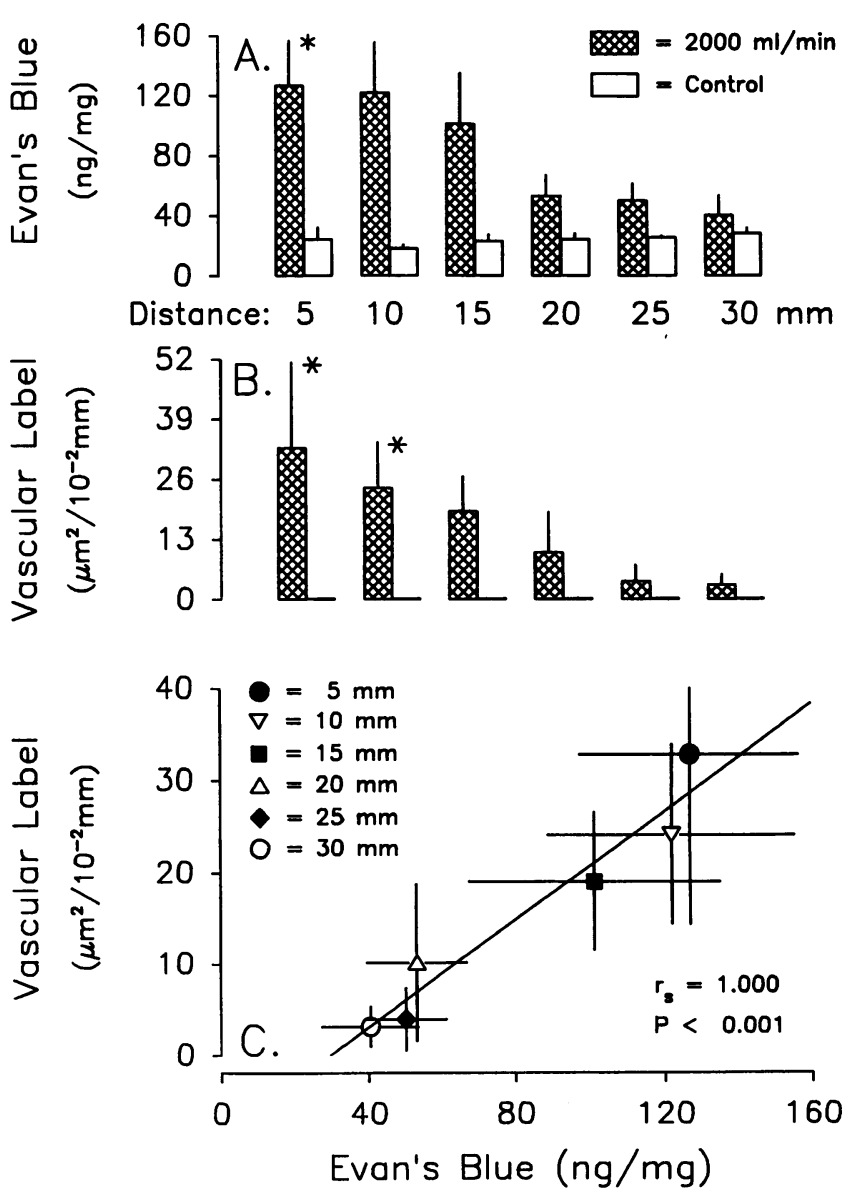

Figure 3. Hyperpnea-induced extravasation of Evan's blue dye and colloidal label. Extravasation of Evan's blue dye $(A)$ and monastral blue $B(B)$ in dry air challenged $(2,000 \mathrm{ml} / \mathrm{min}$ for $5 \mathrm{~min})$ and control $(200 \mathrm{ml} / \mathrm{min}$ ) airways as a function of distance from the tip of a wedged bronchoscope. $(C)$ Extravasation of colloidal label and Evan's blue dye as a function of distance from the tip of a bronchoscope. Evan's blue: $n=5$. Colloidal label: at $5 \mathrm{~mm} n=4,10 \mathrm{~mm} n=7,15 \mathrm{~mm} n=4$, $20 \mathrm{~mm} n=4,25 \mathrm{~mm} n=2$, and $30 \mathrm{~mm} n=5$. Values represent mean \pm se. $* P \pm 0.05$, comparison of $2,000 \mathrm{ml} / \mathrm{min}$ to control.

\section{MORPHOMETRIC ANALYSIS OF AIRWAYS WITH AND WITHOUT} BBF

A total of 128 airway rings (AR) from five dogs were examined. The average diameter of bronchi and bronchioles was $3.28 \pm 0.08(\mathrm{AR}=62)$ and $1.80 \pm 0.08 \mathrm{~mm}(\mathrm{AR}=66)$, respectively.

Dry air-induced bronchovascular leakage. DAC significantly increased bronchovascular leakage in normal dry air challenged bronchi and bronchioles (Fig. 4 A). Although bronchovascular leakage occurred primarily in the lamina propria (Fig. $4 B$ ), similar trends were evident in the submucosa of all airways (Fig. $4 C$ ). Despite statistically significant differences, microvascular leakage was virtually absent in normal control, ligated control, and ligated dry air exposed airways.

Hyperpnea-induced mucosal injury. Although DAC did, ligation of the bronchial artery did not in itself result in mucosal injury (Fig. $5 \mathrm{~A}$ ). The percentage of dry air-induced damage did not differ significantly in normal and ligated bronchi (Fig. $5 \mathrm{~B}$ ). In contrast, $45 \pm 15 \%$ of the mucosa in ligated dry air exposed bronchioles was damaged, compared to only $14 \pm 7 \%$ 

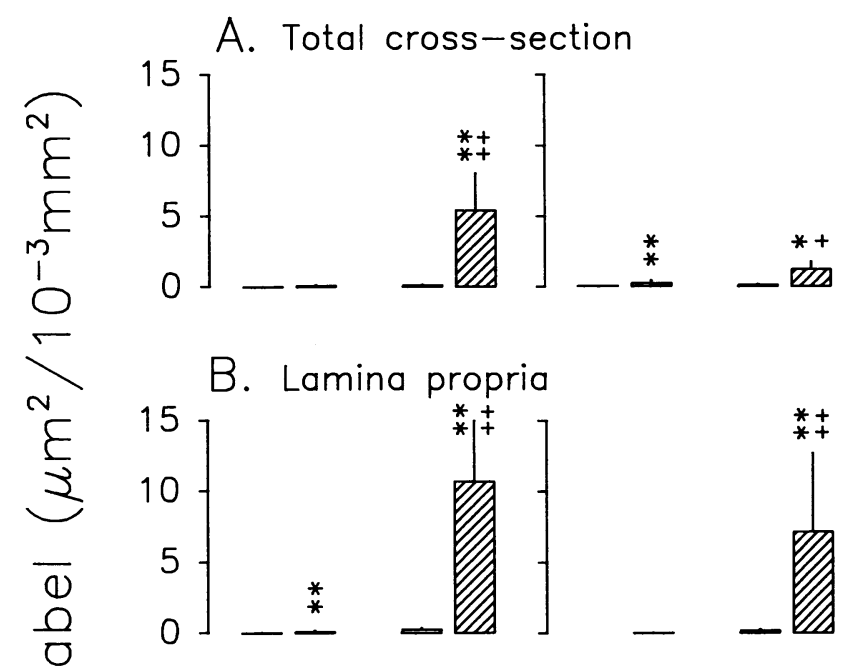

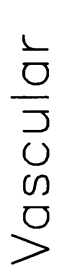

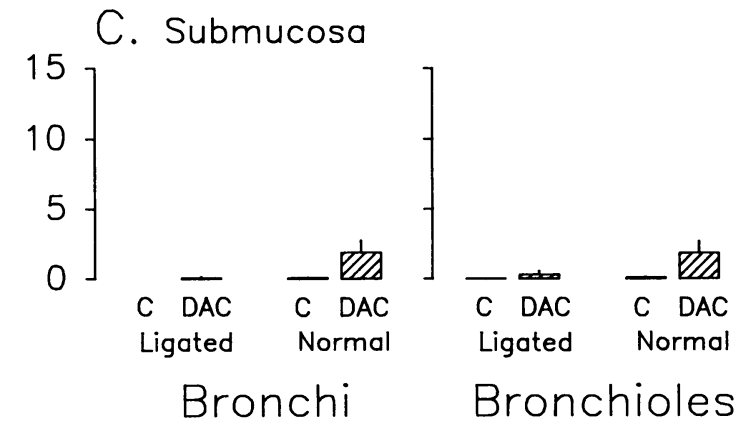

Figure 4. Effect of lobar bronchial artery ligation on hyperpnea-induced extravasation of vascular label. Colloidal carbon $/ \mu \mathrm{m}^{2}$ of control (open bar) and dry air challenged (hatched bar) airways with either a normal or ligated bronchial circulation. Data are expressed as an average over the entire cross-section $(A)$, the lamina propria $(B)$, and the submucosa $(C)$. Values represent mean \pm SEM. $* P \leq 0.05, * * P \leq 0.01$ when compared to control. ${ }^{\dagger} P \leq 0.05,{ }^{\ddagger} P \leq 0.01$ when compared with similarly treated ligated airway. $n=5$.

$(P \leq 0.05)$ of the mucosa of normally perfused bronchioles (Fig. 5 C).

Hyperpnea-induced goblet cell secretion. DAC significantly decreased $(P \leq 0.01) \mathrm{G} / \mathrm{C}$ ratios in normal and ligated airways (Fig. $6 \mathrm{~A}$ ). Although these changes were most prominent in dry air-challenged bronchi (Fig. $6 \mathrm{~B}$ ), similar changes also occurred in bronchioles (Fig. $6 C$ ).

Hypernea-induced changes in mast cell number. DAC and ligation each decreased the total number of intact mast cells in sublobar bronchi (Fig. $7 A$ ). DAC and ligation each decreased intact mast cell numbers in the lamina propria of bronchi and bronchioles, and the dry air-induced effect was significantly greater $(\mathrm{P} \leq 0.01)$ in ligated airways (Fig. $7 \mathrm{~B})$. Although DAC did not affect mast cell number in the submucosa of normal bronchi or bronchioles, ligation did decrease mast cell number in bronchi $(P \leq 0.05)$, and mast cell number was further reduced by DAC (Fig. $7 C$ ).

Hyperpnea-induced infiltration of leukocytes. Bronchial artery ligation reduced baseline inflammatory cell number, and either abolished or inhibited dry air-induced inflammatory cell influx in bronchi and bronchioles (Fig. $8 \mathrm{~A}$ ). Although DAC did not increase inflammatory cell number in ligated bronchi,

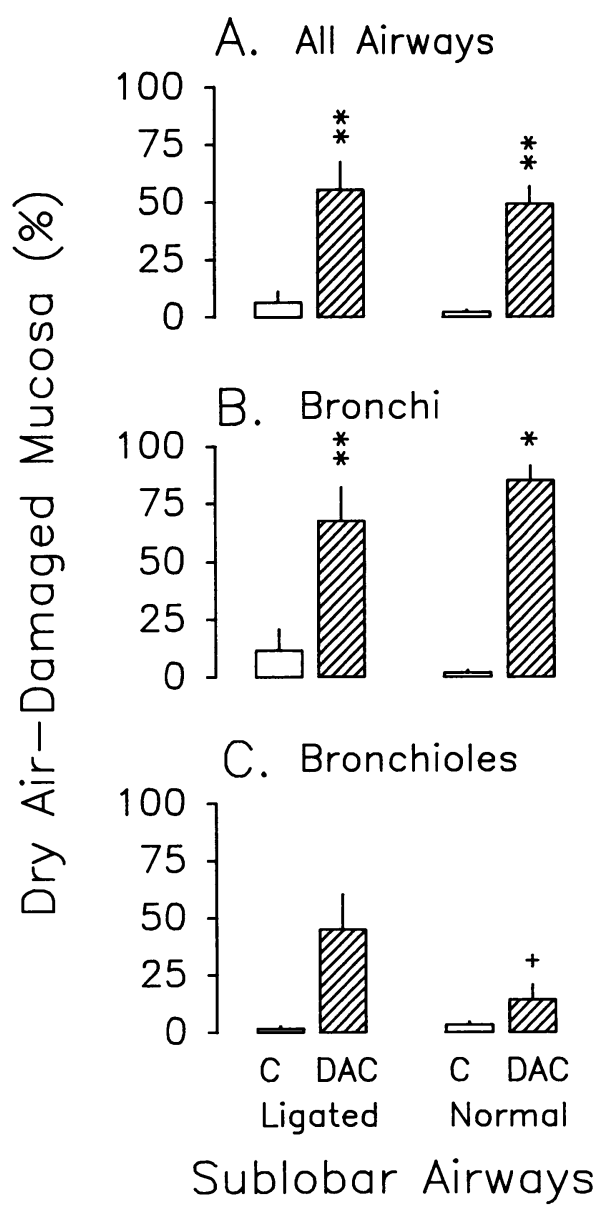

Figure 5. Effect of lobar bronchial artery ligation on hyperpnea-induced mucosal injury. Percentage of airway perimeter occupied by damaged mucosa in control (open bar) and dry air challenged (hatched bar) airways with normal and ligated bronchial circulation. Data are expressed as an average over all airways $(A)$, for bronchi only $(B)$, and for bronchioles only $(C)$. Values represent mean \pm SEM. ${ }^{*} P \leq 0.05$, $* * P \leq 0.01$ when compared with control. ${ }^{+} P \leq 0.05$ when compared with similarly treated ligated airway. $n=5$.

it significantly increased cell numbers in the lamina propria (Fig. $8 \mathrm{~B}$ ) and submucosa (Fig. $8 \mathrm{C}$ ) of ligated bronchioles.

Hyperpnea-induced changes in bronchial vessel diameter. DAC increased ( $\mathrm{p} \leq 0.05$ ) bronchial vessel diameter (Fig. 9). Bronchial artery ligation alone increased $(P \leq 0.05)$ vessel diameter in the lamina propria of unchallenged control airways and enhanced $(P \leq 0.05)$ dry air-induced vasodilation (Fig. 9 $B$ ). Submucosal vessels were affected by DAC similarly (Fig. 9 C).

\section{Discussion}

We used three different methods to evaluate the role of the bronchial circulation in the development of HIAO. No difference was observed when we compared airway responses to a single DAC done in either a sublobar region with $\mathrm{BBF}$ or a contralaterally located lobe without BBF (Fig. $2 A$ ). Similar results were recorded in response to repeated challenges done in the same sublobar location during intermittent periods of normal and impaired lobar BBF (Fig $2 B$ ). Finally, DAC done 


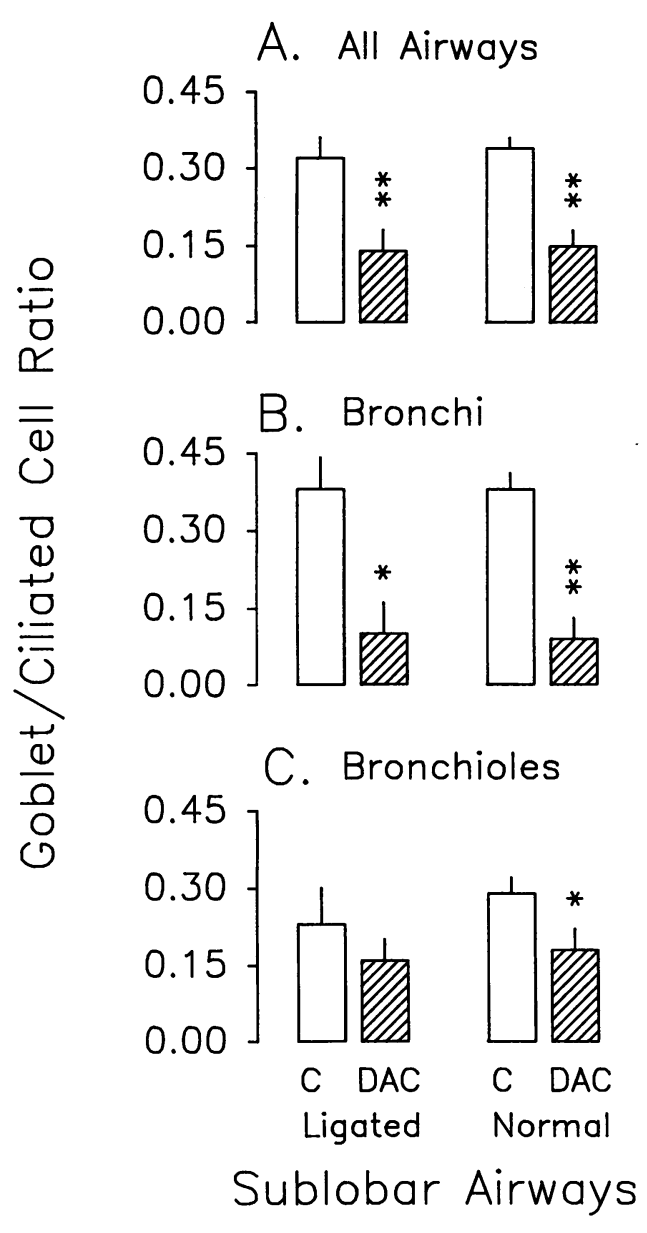

Figure 6. Effect of lobar bronchial artery ligation on hyperpnea-induced changes in goblet cell/ciliated cell $(\mathrm{G} / \mathrm{C})$ ratios. $\mathrm{G} / \mathrm{C}$ ratio in control (open bar) and dry air challenged (hatched bar) airways with normal and ligated bronchial circulation. Data are expressed as an average over all airways $(A)$, for bronchi only $(B)$, and for bronchioles only $(C)$. $* P \leq 0.05, * * P \leq 0.01$ when compared with control. $n=5$.

post mortem in dogs with pulmonary but no bronchial perfusion elicited a normal obstructive response (Fig. $2 C$ ). In addition, prolonged cooling in postmortem dogs attenuated HIAO in a fashion similar to that seen in vivo in dogs $(16,22,23)$ and in man (12). All three experiments demonstrate that peripheral airway obstruction develops regardless of the presence or absence of BBF. However, it is possible that our method of lobar ligation did not completely abolish BBF, and that an impaired flow was sufficient to produce bronchovascular leakage and airway obstruction. It is also possible that either occlusion of the bronchovasculature or death stopped systemic bronchial perfusion, but did not prevent retrograde pulmonary perfusion (24) from contributing to hyperpnea-induced bronchovascular leakage and airway obstruction. In addressing these possibilities, we examined the efficacy of our method of bronchial occlusion, and hyperpnea-induced changes in normal and ligated airways.

Before examining the efficacy of our bronchial artery occlusion technique, we evaluated two different intravascular labels commonly used to estimate bronchovascular leakage. Evan's blue dye is an easily quantified marker of plasma albumin extravasation (17). In contrast, colloidal carbon and monastral blue B are macromolecular tracers consisting of 20 - to $50-\mathrm{nm}$ -

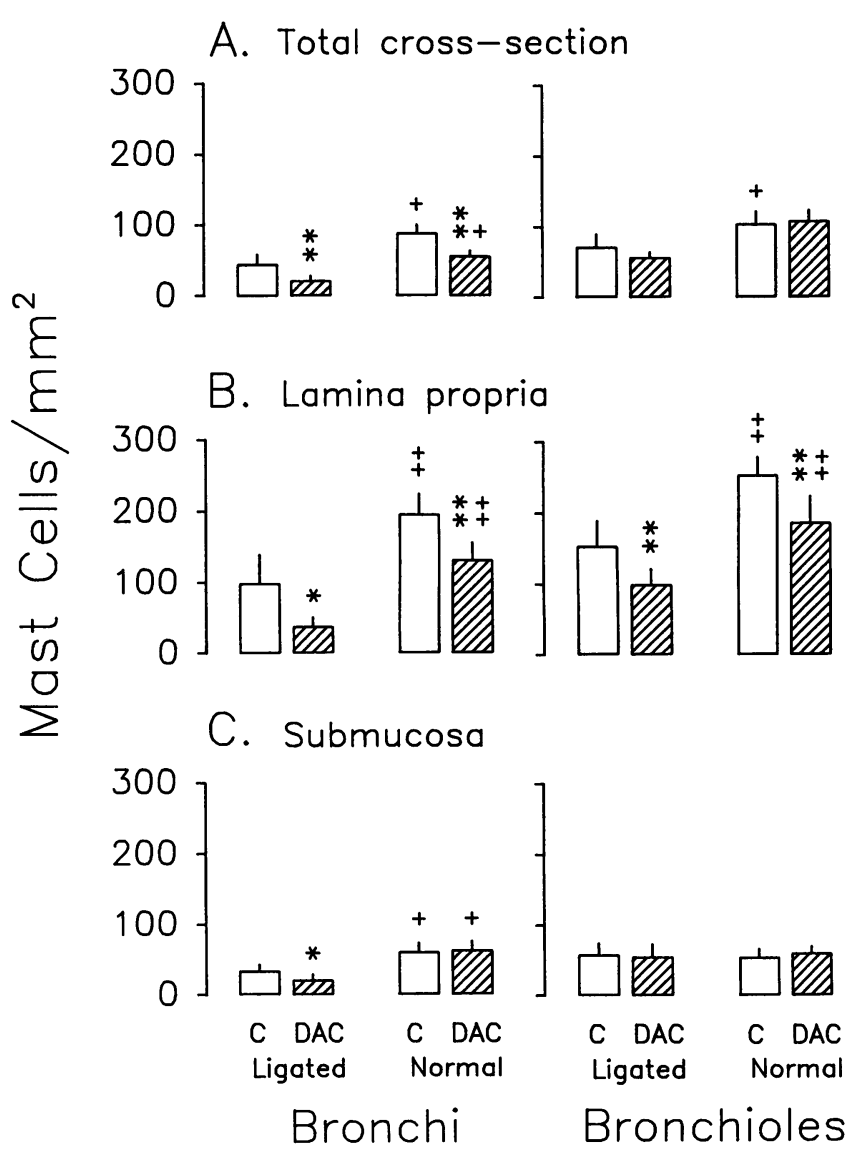

Figure 7. Effect of lobar bronchial artery ligation on hyperpnea-induced changes in intact mast cell density. Mast cells $/ \mathrm{mm}^{2}$ in control (open bar) and dry air challenged (hatched bar) airways with normal and ligated bronchial circulation. Data are expressed as an average over the entire cross-section $(A)$, the lamina propria $(B)$, and the submucosa (C). Values represent mean \pm SEM. $* P \leq 0.05, * * P \leq 0.01$ when compared to control. ${ }^{\dagger} P \leq 0.05,{ }^{\ddagger} P \leq 0.01$ when compared with similarly treated ligated airway. $n=5$.

wide particles $(25,26)$ that can pass between leaky endothelial cells and become trapped in the walls of hyperpermeable vessels. Previous experiments revealed that the extravasation of either tracer can be used to localize and quantify the bronchovascular leakage in canine peripheral airways after hyperventilation with cool dry air (8). Although the quantification of extravasated colloidal label is significantly more time consuming than quantification of Evan's blue, it allows the collection of relevant morphometric data that are normally lost when using the latter method. Because the use of colloidal particles to quantify bronchovascular leakage in bronchi and bronchioles has not been previously validated, we compared our morphometric method for estimating microvascular leakage in peripheral airways with the more commonly used Evan's blue method. Hyperpnea-induced extravasation of Evan's blue was greatest in large bronchi $(\sim 130 \mathrm{ng} / \mathrm{mg}$ ) closest to the wedged bronchoscope, decreased with increasing distance from the scope, and was markedly enhanced when compared with control airways $(\sim 25 \mathrm{ng} / \mathrm{mg})$ located in adjacent sublobar segments (Fig. $3 \mathrm{~A}$ ). This proximal greater than distal hyperpnea-induced extravasation of Evan's blue is qualitatively similar to that reported in guinea pigs, which was also unrelated to the severity of the pulmonary ob- 


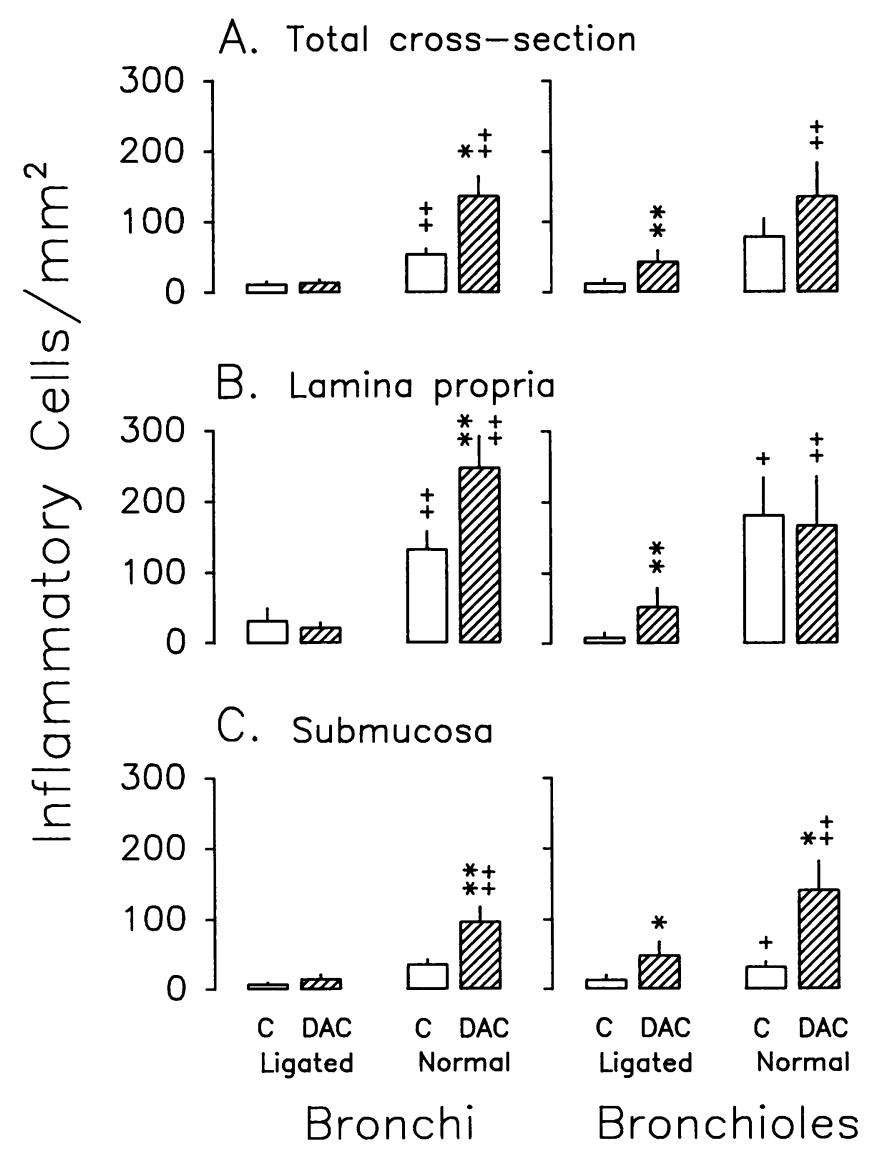

Figure 8. Effect of lobar bronchial artery ligation on hyperpnea-induced leukocyte infiltration. Inflammatory cells $/ \mathrm{mm}^{2}$ of control (open bar) and dry air challenged (hatched bar) airways with either a normal or ligated bronchial circulation. Data are expressed as an average over the entire cross-section $(A)$, the lamina propria $(B)$, and the submucosa (C). Values represent mean \pm SEM. ${ }^{*} P \leq 0.05,{ }^{*} P \leq 0.01$ when compared with control. ${ }^{\dagger} P \leq 0.05,{ }^{\ddagger} P \leq 0.01$ when compared with similarly treated ligated airway. $n=5$.

struction (11). Similar trends in hyperpnea-induced bronchovascular leakage were revealed by the extravasation of colloidal label in canine peripheral airways (Fig. $3 \mathrm{~B}$ ). This distancedependent change in bronchovascular permeability probably reflects the progressive conditioning of dry air as it penetrates deeper into the lung periphery. A comparison of hyperpneainduced microvascular leakage as determined by Evan's blue and colloidal label at similar locations along identically challenged sublobar airways indicates that both methods yield similar qualitative results (Fig. $3 \mathrm{C}$ ). However, the use of a colloidal label eliminates the potential effect of tissue handling time on the magnitude of leakage, and allows the exact localization of the sites of fluid extravasation.

The efficacy of our bronchial artery occlusion technique was examined via the intravenous injection of colloidal label just before DAC. If bronchial artery occlusion was complete, BBF would cease and transmural bronchovascular pressure would be markedly reduced. The absence of BBF would act to exclude circulating label from the occluded region, and the resulting decrease in transmural pressure would reduce extravasation of any label that entered the challenged region. Quantification of colloidal label in hyperpnea-challenged airways from
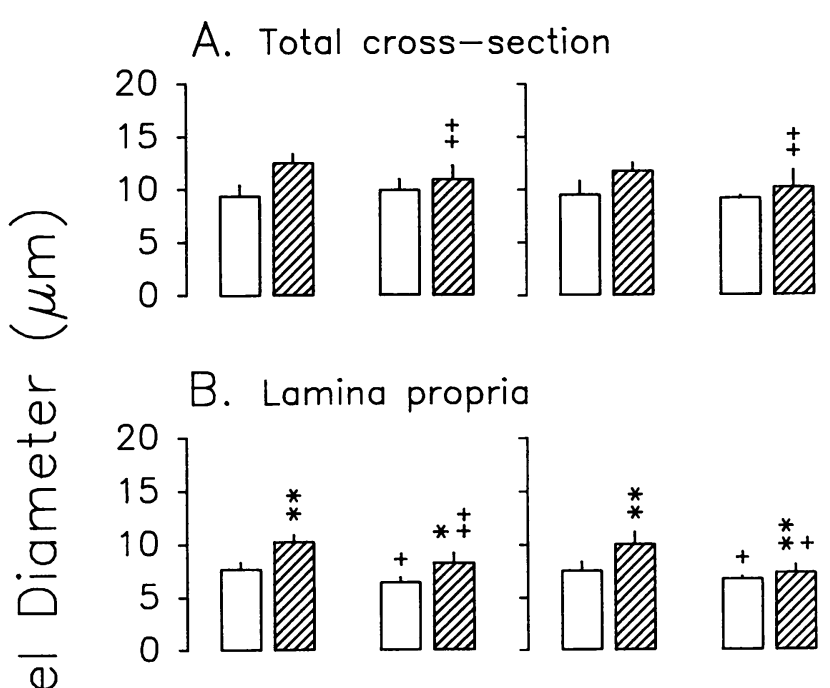

$\overline{0}$
0
0
0
$>$

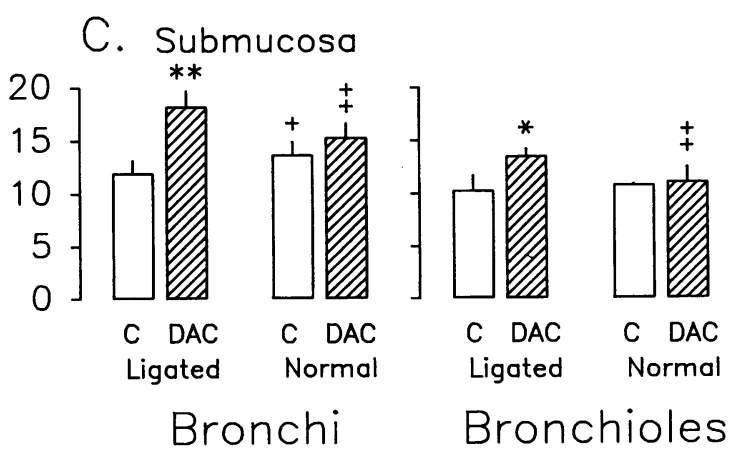

Figure 9. Effect of lobar bronchial artery ligation on hyperpnea-induced changes in vessel diameter. Average vessel diameter in control (open bar) and dry air challenged (diagonal bar) airways with either a normal or ligated bronchial circulation. Data are expressed as an average over the entire cross-section $(A)$, the lamina propria $(B)$, and the submucosa (C). Values represent mean \pm SEM. $* P \leq 0.05, * * P \leq 0.01$ when compared with control. ${ }^{\dagger} P \leq 0.05,{ }^{\ddagger} P \leq 0.01$ when compared with similarly treated ligated airway. $n=5$

lobes with and without BBF revealed that leakage was virtually abolished in ligated lobes (Fig. 4). This indicates that BBF to bronchi and bronchioles located downstream from the occluder was significantly impaired if not abolished, and that retrograde pulmonary blood flow did not substitute in its absence. These data, in conjunction with our experiments documenting normal HIAO in the absence of BBF (Fig. 2), clearly show that the bronchial circulation does not contribute to the development of HIAO.

Although BBF does not appear to be obligatory for the development of hyperpnea-induced airway narrowing, morphometric analysis of normal and ligated airways suggests that the bronchial circulation does modulate peripheral airway responses to airway desiccation. Morphometric analysis revealed that occlusion of the bronchial artery did not in itself result in mucosal injury (Fig. 5). DAC damaged $\sim 50 \%$ of the airway perimeter in sublobar segments regardless of the status of the bronchial circulation (Fig. $5 \mathrm{~A}$ ) . Approximately $75 \%$ of the mucosal perimeter was damaged in bronchi located in normal and in ligated segments (Fig. $5 \mathrm{~B}$ ). In contrast, mucosal damage in dry air exposed ligated bronchioles was three times greater than the hyperpnea-induced damage in bronchioles with intact BBF 
(Fig. $5 C$ ). Previous work revealed that DAC in intact dogs resulted in significant mucosal injury only in the bronchi (8). Data presented here indicate that impairment or abolition of BBF results in hyperpnea-induced damage to the bronchiolar epithelium. These data are consistent with the hypothesis that an intact bronchial circulation reduces mucosal damage by limiting stimulus penetration into the bronchiolar region. In a similar fashion, $\beta$-agonists may in part inhibit dry air-induced mucosal injury in canine bronchi (27) by increasing BBF and ablating the stimulus to those airways. However, the direct cause of hyperpnea-induced epithelial damage remains a mystery. We previously suggested that microvascular leakage contributes to epithelial injury (8): an increase in interstitial pressure during smooth muscle constriction could disrupt the bronchial epithelium. The fact that mucosal injury in this study is evident in the absence of bronchovascular leakage indicates that fluid extravasation either alone or in conjunction with smooth muscle constriction, is unlikely to be the primary cause of hyperpneainduced airway epithelial damage.

The G/C ratio averaged over all airways was $\sim 0.33$ and tended to be larger in bronchi than in bronchioles (Fig. 6). We previously reported that goblet cells were distributed heterogeneously throughout the canine lung periphery, that $\mathrm{G} / \mathrm{C}$ ratio decreased with decreasing airway diameter, and that challenge with warm-moist air significantly reduced goblet cell discharge (8). A decrease in G/C ratio reflects an increase in goblet cell secretion. This study shows that systemic blood flow to bronchi and bronchioles affects neither $\mathrm{G} / \mathrm{C}$ ratios in unchallenged segments nor hyperpnea-induced goblet cell degranulation in the peripheral lung (Fig. 6). This is consistent with our previous observation that a $\beta$-agonist, which may result in transient dilation of the bronchial circulation during DAC, did not alter goblet cell secretion (27).

The occlusion of lobar BBF decreased mast cell number in control bronchi and bronchioles, and DAC decreased this number even further in the lamina propria (Fig. 7). Because completely degranulated mast cells would not be detected by our morphometric analysis, a reduction in mast cell number reflects an increase in mast cell degranulation and activity. Thus, impaired BBF and DAC independently cause mast cell degranulation, and in combination appear to have an additive effect. The mechanisms by which impaired blood flow and DAC cause mast cell degranulation are unknown. Mast cell degranulation also occurs in dogs after pulmonary artery occlusion and reperfusion (28). This may be related to local changes in oxygen radical production in the lung either during the period of ischemia or during reperfusion (29). Although reperfusion could have been a factor in our repeated challenge experiments (Fig. $2 B$ ), sublobar segments were not reperfused in either our single DAC (Fig. $2 A$ ) or our postmortem (Fig. $2 C$ ) experiments. Although it is unclear whether reperfusion is necessary for oxidant-induced injury to occur in canine lungs (28), our experiments reveal that occlusion alone causes mast cell degranulation. It is possible that ischemia- and hyperpnea-induced mast cell degranulation are associated with the development of local airway hypertonicity, a stimulus reported to cause mast cell mediator release in vitro (30) and in vivo (31).

Hyperpnea-induced leukocyte infiltration into the lamina propria and submucosa was markedly reduced in ligated, dry air challenged bronchi and bronchioles when compared to normally perfused airways (Fig. 8), again confirming the absence of $\mathrm{BBF}$ to these ligated regions. Although DAC had no effect on leukocyte infiltration in ligated bronchi, it did increase inflammatory cell density in ligated bronchioles when compared to their ligated controls (Fig. 8). This hyperpnea-induced leukocyte influx in bronchioles likely reflects the close proximity of the pulmonary capillaries to the airway lumen. Alternatively, it is possible that this small increase in leukocyte density results from the local release of a chemotactic factor. The fact that hyperpnea-induced airway narrowing occurs in airways lacking bronchial circulation implies that leukocyte influx does not play an important role in this acute response. The postchallenge role of these inflammatory cells remains to be investigated, but from the time-course of infiltration (32) it seems reasonable to conclude that they may be instrumental in the development of the "late" response previously characterized in this canine model $(32,33)$. These results are similar to those obtained with other airway irritants $(34,35)$, and leukocyte infiltration may contribute to the prolonged period of bronchovascular hyperpermeability that is initiated by DAC (32). Prolonged bronchovascular leakage and leukocyte infiltration may also play an important role in the mucosal repair which is evident between 2 and 24 $h$ after DAC (32).

Ligation of the bronchial artery increased the average bronchial vessel diameter in the lamina propria from $6.4 \mu \mathrm{m}$ in normal airways to $7.7 \mu \mathrm{m}$ in ligated control airways (Fig. 9 $B)$. Hyperpnea with dry air further increased vessel diameter $(8.2 \mu \mathrm{m})$, and the lack of BBF enhanced this effect $(10.2 \mu \mathrm{m})$. With the exception of an increased vessel diameter in dry air exposed normal airways, similar trends were observed for submucosal vessels (Fig. 9 C). Based on Laitinen et al. (36), bronchial venules (10-30 $\mu$ m diameter) and capillaries (4-9 $\mu \mathrm{m}$ diameter) appear to be important sites of vascular leakage in this model (Fig. 9). However, we cannot rule out the possibility that arterioles (15-40 $\mu \mathrm{m}$ diameter) may also be involved. Our data supports the hypothesis that DAC causes mast cell degranulation (Fig. 7), and results in bronchovascular dilatation (Fig. 9) and hyperpermeability (Fig. 4). The increase in vessel diameter seen in the lamina propria of normal dry air challenged bronchioles and bronchi (Fig. $9 \mathrm{~B}$ ) would theoretically increase BBF to those airways by 1.4- and 2.7-fold, respectively. This is consistent with the intravascular radiolabeled microsphere data showing that hyperpnea with dry air increases canine BBF $(9,10)$. In contrast, the hyperpnea-induced change in submucosal vessel diameter is unlikely to significantly alter blood flow to the submucosa of either normal bronchi or bronchioles (Fig. $9 \mathrm{C}$ ). However, regardless of size or location, vessel diameter in dry air challenged ligated airways is significantly larger than those in normally perfused airways. This observation is consistent with a hyperpnea-induced release of vasodilator mediators that accumulate in segments without BBF. The identity of these potential mediators is unknown, and although local bronchial perfusion may provide intravascular clearance of these purported vasoactive mediators $(37,38)$, our data do not preclude an extravascular origin.

In summary, the absence of BBF, as indicated by a marked reduction in hyperpnea-induced bronchovascular labeling, does not contribute to the development of HIAO. Although BBF is not a prerequisite for the development of hyperpnea-induced airway narrowing, it does provide the bronchial mucosa with significant protection from dry air-induced injury. Although BBF does not affect goblet cell secretion, its absence causes mast cell degranulation in unchallenged segments and enhances mast cell degranulation in response to hyperpnea with dry air. In 
addition, hyperpnea-induced leukocyte infiltration is markedly reduced in ligated, dry air challenged airways, confirming their passive role in the acute response to dry air. Finally, hyperpnea with dry air causes airway vasodilation, which is enhanced in the absence of BBF.

In conclusion, occlusion of lobar BBF abolishes bronchovascular leakage and increases dry air-induced mucosal injury, but fails to affect HIAO. We speculate that under normal conditions, hyperpnea-induced bronchovascular dilation and leakage protects the bronchial mucosa from dry air-induced injury. This protection may reflect a basic homeostatic mechanism in which the replacement of water lost during hyperpnea would serve to ameliorate airway injury and help to maintain normal airway hydration.

\section{Acknowledgments}

The authors wish to thank Ms. Judith Corum, Mr. Dick Rabold, and Mr. Charles Stream for their superb technical assistance. We gratefully acknowledge the statistical counseling provided by Dr. A.W. Kimball, Jr., Alumni Centennial Professor of Biostatistics, at Johns Hopkins University.

This work was supported in part by National Institutes of Health grants HL39406, HL51930, and ES03819.

\section{References}

1. Chapman, R. W., and G. Danko. 1985. Hyperventilation-induced bronchoconstriction in guinea pigs. Int. Arch. Allergy Appl. Immunol. 78:190-196.

2. Badier, M., P. Barthelemy, M. Soler, and Y. Jammes. 1988. In vivo and in vitro studies on cold-induced airway response in normal and sensitized rabbits. Respir. Physiol. 72:1-10.

3. Jammes, Y., P. Barthelemy, and S. Delpierre. 1983. Respiratory effects of cold air breathing in anesthetized cats. Respir. Physiol. 54:41-54.

4. Freed, A. N., B. Bromberger-Barnea, and H. A. Menkes. 1985. Dry airinduced constriction in lung periphery: a canine model of exercise-induced asthma J. Appl. Physiol. 59:1986-1990.

5. Biagini, R. E., J. C. Clark, W. J. Moorman, and E. A. Knecht. 1991. Evaluation of the onset and duration of response to cold air inhalation challenge in cynomolgus monkeys (Macaca fascicalaris). J. Appl. Toxicol. 44:1-6.

6. Ray, D. W., C. Hernandez, N. Munoz, A. R. Leff, and J. Solway. 1988 Bronchoconstriction elicited by isocapnic hyperpnea in guinea pigs. J. Appl. Physiol. 65:934-939.

7. Pliss, L. B., E. P. Ingenito, R. H. Ingram, and B. Pichurko. 1990. Assessment of bronchoalveolar cell and mediator response to isocapnic hyperpnea in asthma. Am. Rev. Respir. Dis. 142:73-78.

8. Freed, A. N., C. Omori, B. H. Schofield, and W. Mitzner. 1994. Dry airinduced mucosal cell injury and bronchovascular leakage in canine peripheral airways. Am. J. Respir. Cell Mol. Biol. 11:724-732.

9. Baile, E. M., R. W. Dahlby, B. R. Wiggs, G. H. Parsons, and P. D. Paré. 1987. Effect of cold and warm dry air hyperventilation on canine airway blood flow. J. Appl. Physiol. 62:526-532.

10. Baile, E. M., D. J. Godden, and P. D. Paré. 1990. Mechanism for increase in tracheobronchial blood flow induced by hyperventilation of dry air in dogs. $J$. Appl. Physiol. 68:105-112.

11. Garland, A., D. W. Ray, C. M. Doerschuk, L. Alger, S. Eappon, H Hernandez, M. Jackson, and J. Solway. 1991. Role of tachykinins in hyperpneainduced bronchovascular hyperpermeability in guinea pigs. J. Appl. Physiol. 70:27-35.

12. McFadden, E. R., Jr., K. A. M. Lenner, and K. P. Strohl. 1986. Postexertional airway rewarming and thermally induced asthma. J. Clin. Invest. 78:18 25.

13. Xuan, A. T. D., M. Chaussain, J. Regnard, and Lockhart. 1989. Pretreat- ment with an inhaled $\alpha_{1}$-adrenergic agonist, methoxamine, reduces exercise-induced asthma. Eur. Respir. J. 2:409-414.

14. Gilbert, I. A., C. J. Winslow, K. A. Lenner, J. A. Nelson, and J. R. McFadden, Jr. 1993. Vascular volume expansion and thermally induced asthma. Eur. Respir. J. 6:189-197.

15. Freed, A. N., D. Wang, and H. A. Menkes. 1987. Dry-air induced constriction: effects of pharmacological intervention and temperature. J. Appl. Physiol. 62:1794-1800.

16. Freed, A. N., L. J. Kelly, and H. A. Menkes. 1987. Airflow-induced bronchospasm: imbalance between airway cooling and airway drying. Am. Rev. Respir. Dis. 136:595-599.

17. Saria, A., and J. M. Lundberg. 1983. Evans blue fluorescence: quantitative and morphological evaluation of vascular permeability in animal tissues. J. Neurosci. Methods. 8:41-49.

18. James, A. L., J. C. Hogg, L. A. Dunn, and P. D. Paré. 1988. The use of the internal perimeter to compare airway size and to calculate smooth muscle shortening. Am. Rev. Respir. Dis. 138:136-139.

19. Bai, A., D. H. Eidelman, J. C. Hogg, A. L. James, R. K. Lambert, M. S. Ludwig, J. Martin, D. M. McDonald, W. A. Mitzner, M. Okazawa, R. J. Pack, P. D. Par̀, R. R. Schellenberg, H. A. W. M. Tiddens, E. M. Wagner, and D. Yager. 1994. Proposed nomenclature for quantifying subdivisions of the bronchial wall. J. Appl. Physiol. 77:1011-1014.

20. Zar, J. H. 1974. Biostatistical Analysis. Prentice-Hall, Inc., Englewood Cliffs, NJ. 620 pp.

21. Freed, A. N. 1989. Regional and temporal variation in canine peripheral lung reponses to dry air. J. Appl. Physiol. 67(5):1727-1733.

22. Freed, A. N., and C. E. Stream. 1991. Airway cooling: stimulus specific modulation of airway responsiveness in the canine lung periphery. Eur. Respir. J. 4:568-574.

23. Freed, A. N., S. D. Fuller, and C. E. Stream. 1991. Transient airway cooling modulates dry-air-induced and hypertonic aerosol-induced bronchoconstriction. Am. Rev. Respir. Dis. 144:358-362.

24. Baile, E. M., D. Minshall, P. M. Dodek, and P. D. Paré. 1994. Blood flow to the trachea and bronchi: the pulmonary contribution. J. Appl. Physiol. 76:20632069.

25. Joris, I., U. DeGirolami, K. Wortham, and G. Majno. 1982. Vascular labelling with monastral blue B. Stain Technol. 57:177-183.

26. Hulstrom, D., L. Malmgren, D. Gilstring, and Y. Olsson. 1983. FITCDextrans as tracers for macromolecular movements in the nervous system. Acta Neuropathol (Berl). 59:53-62.

27. Omori, C., B. H. Schofield, W. Mitzner, and A. N. Freed. 1995. A $\beta_{2-}$ adrenergic agonist inhibits dry air-induced injury in canine peripheral airways. $J$. Appl. Physiol. 78:2169-2179.

28. Su, M., E. Y. Chi, M. J. Bishop, and W. R. Henderson, Jr. 1993. Lung mast cells increase in number and degranulate during pulmonary artery occlusion/ reperfusion injury in dogs. Am. Rev. Respir. Dis. 147:448-456.

29. Koyama, I., T. J. K. Toung, M. C. Rogers, G. H. Gurtner, and R. J. Traystman. 1987. $\mathrm{O}_{2}$ radicals mediate reperfusion lung injury in ischemic $\mathrm{O}_{2^{-}}$ ventilated canine pulmonary lobe. J. Appl. Physiol. 63:111-115.

30. Eggleston, P. A., A. Kagey-Sobotka, and L. M. Lichtenstein. 1987. A comparison of the osmotic activation of basophils and human lung mast cells. Am. Rev. Respir. Dis. 135:1043-1048.

31. Silber, G., D. Proud, J. Warner, R. Naclerio, A. Kagey-Sobotka, L. Lichtenstein, and P. Eggleston. 1988. In vivo release of inflammatory mediators by hyperosmolar solutions. Am. Rev. Respir. Dis. 137:606-612.

32. Omori, C., B. H. Schofield, W. Mitzner, and A. N. Freed. 1995. Hyperpnea with dry air causes time-dependent alterations in mucosal morphology and bronchovascular permeability. J. Appl. Physiol. 78:1043-1051.

33. Freed, A. N., and N. F. Adkinson, Jr. 1990. Dry air-induced late phase responses in the canine lung periphery. Eur. Respir. J. 3:434-440.

34. Hulbert, W. C., D. C. Walker, A. Jackson, and J. C. Hogg. 1981. Airway permeability to horseradish peroxidase in guinea pigs: the repair phase after injury by cigarette smoke. Am. Rev. Respir. Dis. 123:320-326.

35. Murlas, C. G., and J. H. Roum. 1985. Sequence of pathologic changes in the airway mucosa of guinea pigs during ozone-induced bronchial hyperreactivity. Am. Rev. Respir. Dis. 131:314-320.

36. Laitinen, A., L. A. Laitinen, R. Moss, and J. G. Widdicombe. 1989. Organisation and structure of the tracheal and bronchial blood vessels in the dog. J. Anat. 165:133-140.

37. Kelly, L., J. Kolbe, W. Mitzner, E. W. Spannhake, B. Bromberger-Barnea, and $\mathrm{H}$. Menkes. 1986. Bronchial blood flow affects recovery from constriction in dog lung periphery. J. Appl. Physiol. 60:1954-1959.

38. Wagner, E. M., and W. A. Mitzner. 1990. Bronchial circulatory reversal of methacholine-induced airway constriction. J. Appl. Physiol. 69:1220-1224. 